\title{
Tres poemas amadisianos de Pere Gimferrer, José Manuel Lucía Megías y Luis Alberto de Cuenca ${ }^{1}$
}

\author{
Three Amadisian Poems by Pere Gimferrer, \\ José Manuel Lucía Megías and Luis Alberto de Cuenca \\ Rafael M. Mérida \\ (Universitat de Lleida)
}

\section{RESUMEN}

Análisis literario de las representaciones de Urganda la Desconocida en textos poéticos de Luis Alberto de Cuenca, Pere Gimferrer y José Manuel Lucía Megías, publicados a partir de 1985. La Desconocida es uno de los seres sobrenaturales más originales de las letras hispánicas. El sincretismo que revelan sus orígenes sufrió una profunda revisión a lo largo del Amadís de Gaula, de Garci Rodríguez de Montalvo, factor que redundó en su importancia en el imaginario literario del siglo XVI. De la mano de tres de los poetas que mejor conocen la tradición literaria del Medioevo, se valorarán las significaciones éticas y estéticas de esta insólita resurrección poética, muy diferente en cada uno de los autores.

\section{Palabras Clave}

Amadís de Gaula. Luis Alberto de Cuenca. Pere Gimferrer. José Manuel Lucía Megías. Poesía española de los siglos XX y XXI.

\begin{abstract}
Literary analysis of the representations of Urganda the Unknown in poetic texts by Luis Alberto de Cuenca, Pere Gimferrer and José Manuel Lucía Megías, published since 1985. The Unknown is one of the most original supernatural beings in Hispanic literature. The syncretism revealed by its origins underwent a profound revision throughout Garci Rodríguez de Montalvo's Amadís de Gaula, a factor that led to its importance in the literary imagination of the 16th century. Three of the poets who best know the medieval literary tradition will show the ethical and aesthetic meanings of this unusual poetic resurrection, very different in each of these authors.
\end{abstract}

\section{KEYWORDS}

Amadís de Gaula. Luis Alberto de Cuenca. Pere Gimferrer. José Manuel Lucía Megías. $20^{\text {th }}$ and $21^{\text {st }}$ century Spanish Poetry.

1. Este trabajo forma parte del proyecto de investigación PID2019-106083GB-I00, del Ministerio de Ciencia e Innovación de España. 
Rebut: $10 / 06 / 2020$

Acceptat: $12 / 07 / 2020$

\section{Urganda la Desconocida y la tradición amadisiana, medieval y renacentista}

Urganda la Desconocida es el personaje más importante de la esfera sobrenatural en el Amadís de Gaula, de Garci Rodríguez de Montalvo, y uno de los seres sobrenaturales más originales de las letras hispánicas del Medioevo. Las fuentes en que está modelada proceden de la materia de Bretaña francesa, como sugiere su parentesco con figuras de la talla del mago Merlín, la Dama del Lago o el hada Morgana, según ya fuera analizado pormenorizadamente (Mérida Jiménez, 2001), combinando rasgos de uno y de otras de manera harto singular: capacidad de auto-transformación -de donde procedería su sobrenombre-, dotes proféticas, conocimiento omnisciente, condición feérica, función protectora del destino del héroe y de su familia, etc. Recordemos uno de sus parlamentos estelares, en el capítulo 2 del Libro I:

- Dígote de aquel que hallaste en la mar que será flor de los cavalleros de su tiempo; éste fará estremecer los fuertes; éste començará todas las cosas y acabará a su honra en que los otros fallescieron; éste fará tales cosas que ninguno cuidaría que pudiessen ser començadas ni acabadas por cuerpo de hombre; éste hará los soberbios ser de buen talante; éste avrá crueza de coraçón contra aquellos que se lo merecieren, y ahún más te digo, que éste será el caballero del mundo que más lealmente manterná amor y amará en tal lugar cual conviene a la su alta proeza [...] (Rodríguez de Montalvo, 1987-1988: 255-256).

Pero tan particular sincretismo, como el que revelan sus orígenes, sufrió una profunda revisión, empezando por una disposición en cuatro libros, con la refundición de Rodríguez de Montalvo a fines del siglo XV de la tradición amadisiana previa, bien conocida en los círculos cortesanos de la Castilla de la centuria precedente ${ }^{2}$. Este factor redundó -a veces paradójicamente- en beneficio de la relevancia de Urganda a lo largo de las diversas tramas narrativas que ensalzan las hazañas de Amadís y su hijo Esplandián, en primera instancia, así como, por extensión, favoreció su presencia en el imaginario literario caballeresco en la España renacentista que reverbera a través de las lecturas de Alonso Quijano, según han valorado Beltrán (1997), Bognolo (1994-1996), Campos García Rojas (2013) o Mérida Jiménez (2008), y que desembarcaría incluso en los virreinatos americanos en forma de mascaradas (Farré Vidal, 2007) ${ }^{3}$.

2. Atendiendo sólo a su presencia en los primeros cuatro libros, su actuación en la trama fue resumida por Juan Manuel Cacho Blecua (Rodríguez de Montalvo, 1987-1988: 1807) de la manera siguiente: «Maga de aspecto cambiante, profetiza el futuro de Amadís a Gandales, tras una aventura de éste con su enamorado (I, 2). Entrega una lanza a Amadís (I, 5) y solicita su ayuda (I, 10), para recuperar a su enamorado. En la investidura de Galaor, le ofrece una espada mágica $(\mathrm{I}, 11)$. Envía a dos doncellas a desencantar a Amadís en el castillo de Arcaláus (I, 19). Mediante unas cartas profetiza a Lisuarte y a Galaor los resultados de la pelea contra Cildadán (II, 57). Se presenta en una extraña fusta en la corte aclarando profecías y sucesos anteriores, y pronunciando unas nuevas profecías (II, 60). Envía unas armas a Perión, a Amadís y a Florestán (III, 68). Mediante una carta profetiza el futuro de Esplandián (III, 71). Llega a la Ínsula Firme en un batel en forma de gran serpiente (IV, 123), aclarando las profecías anteriores, prediciendo el futuro de Maneli y Talanque y Esplandián y acontecimientos futuros. Regala un anillo mágico a Oriana y Amadís para prevenir las acciones de Arcaláus (IV, 126). A instancias suyas, son armados caballeros Esplandián, Ambor, Talanque, Maneli y Garinto, en la nave de la Gran Serpiente. Desaparece misteriosamente (IV, 133)».

3. Una bibliografía más amplia puede encontrarse en Amadís, base de datos de literatura caballeresca integrada en Clarisel (Universidad de Zaragoza): http:// clarisel.unizar.es/ 
Urganda la Desconocida se muestra en sus primeras apariciones en el Libro I de Amadís como un hada benefactora del héroe, pues le entrega una lanza mágica e inicia un atento seguimiento de su trayectoria que incluye su presencia directa e indirecta -por ejemplo, mediante doncellas que cumplen la función de portavoces o de epístolas proféticas- a lo largo de la narración. Anticipando mi análisis, este será el perfil que recoja metafóricamente el poeta Luis Alberto de Cuenca en La caja de plata (1985). La Desconocida participa en momentos de especial resonancia en el desarrollo de la trama, bien sea por su dimensión simbólica -como serían las investiduras de Galaor (I, 11) y de Esplandián (IV, 133)-, bien por su función dinamizadora (II, 57 o IV, 123). En oposición a Arcaláus el Encantador, mago antagonista, Urganda cumple el papel de auxiliar directo a quien se reserva una misión general y, a diferencia de aquél, encarna un modelo progresivamente más cortesano, hasta el punto de transformarse de manera plena en el Libro IV y en las Sergas de Esplandián (quinto libro del ciclo amadisiano) en consejera regia y en portavoz de la ortodoxia religiosa.

Este complejo proceso respondió a la nueva ideología con que Rodríguez de Montalvo bañó su refundición del legado que llegó a sus manos y a la creación de episodios ajenos al original perdido. A lo largo de su Amadís se fuerza un firme deslizamiento de la materia sobrenatural, que parte de la maravilla artúrica (Libro I), transcurre por cauces en los que la magia racionaliza o cristianiza cualquier brote que remotamente se le pueda vincular (sin apenas fisuras en los libros II y III), hasta alcanzar una absoluta asimilación religiosa (Libro IV), cuando llega a introducirse ambiciosamente la noción providencial del «milagro» para justificar y reducir la heterodoxia que pudiera escapar a los límites impuestos. El regidor de Medina del Campo que era Montalvo ofreció, así, una metamorfosis del universo sobrenatural de raigambre más pagana gracias a la presencia de un personaje tan carismático como Urganda la Desconocida.

Su relevancia y talante explican que tanto los continuadores del ciclo amadisiano como muchos otros autores renacentistas se sintieran obligados a introducirla en sus creaciones, ya fuera de manera explícita o implícita, ya como modelo de la magia benéfica, ya como referente genealógico. Aunque Páez de Ribera atacara la heterodoxia de Urganda en su Florisando (1510), no cabe duda de que la Desconocida se convirtió en un modelo casi eximio, según constata su presencia en piezas novelescas, poéticas y teatrales a lo largo de nuestro siglo XVI. Hasta cierto punto, pudiera establecerse un paralelismo con Celestina, pues, al igual que en la obra de Fernando de Rojas, la magia desempeña en Amadís una misión central; ambos personajes femeninos son elogiados o vituperados y, quizás más importante, ambos crearon una progenie de indudable resonancia en la literatura del siglo XVI.

Desde esta perspectiva, por consiguiente, la nueva transformación que sufriría Urganda a manos de Cervantes simbolizaría un homenaje a este ser tan proteico como afortunado. Los primeros versos de cabo roto que albergan la profecía de Urganda la Desconocida, entre los preliminares de la primera parte del Quijote (1605), apuntaban el talante irónico del genial creador hacia los libros de caballerías -con Amadís de Gaula a la cabeza-y revelaban la fama del personaje:

Si de llegarte a los bue-, libro, fueres con letu-, no te dirá el boquirruque no pones bien los de-. Mas si el pan no se te cuepor ir a manos de idio-, verás de manos a bo-, 
aun no dar una en el cla-, si bien se comen las mapor mostrar que son curio-. (Cervantes, 1980: 21)

\section{Urganda la Desconocida en la poesía española reciente: Gimferrer y Lucía Megías}

Curiosamente, cinco siglos después de que Rodríguez de Montalvo imprimiera su sello distintivo en el legado amadisiano precedente y tras casi cuatro centurias de la publicación de la magna obra cervantina, tres poetas españoles han introducido a nuestro personaje en sus versos con propósitos estéticos dispares: Pere Gimferrer (Barcelona, 1945), Luis Alberto de Cuenca (Madrid, 1950) y José Manuel Lucía Megías (Ibiza, 1967). Si bien el presente trabajo abordará con mayor detalle al segundo, no debiera dejar de subrayarse tal coincidencia, pues confirma, ya de entrada, un inusual bagaje literario -e incluso libresco- de los tres autores.

Como se ha tenido ocasión de analizar (Mérida Jiménez, 2016), Pere Gimferrer mostraba una modalidad singular de remisión al universo medieval en Alma Venus (2012), a través de diversas citas y alusiones, como por ejemplo al poeta valenciano del siglo XV Ausiàs March -el personaje descrito en el poema VI del libro segundo de este poemario se llama «Ausías »-. Esto es así porque en este volumen se renueva un original diálogo cultural e intertextual que ya apreciábamos en sus obras compuestas en castellano durante la década de los años 60. Algunas de las remisiones más interesantes aparecen vinculadas a la tradición amadisiana. En el poema IV del libro II del volumen, Gimferrer (2012: 54) introduce el «endriago», monstruo que Montalvo describió como fruto de las relaciones incestuosas entre Bandaguido y su hija, quienes viven en la Ínsola del Diablo y que sería liquidado por el héroe protagonista, metamorfoseado en «Caballero de la Verde Espada $\gg$ (Rodríguez de Montalvo, 1987-1988: 1780 y 1785); Gimferrer lo utiliza simplemente como sinónimo de «dragón», dada su fiereza. En el poema XI de este mismo libro II (Gimferrer, 2012: 69-70), se remite a la tradición de las espadas amadisianas, transformadas en metáforas literarias y eróticas.

No cabe duda, sin embargo, de que el tercero de los ecos amadisianos en Alma Venus sería el de mayor calado, pues se trata de una estelar aparición de Urganda la Desconocida en el poema XI del primer libro, que se inicia con los siguientes versos:

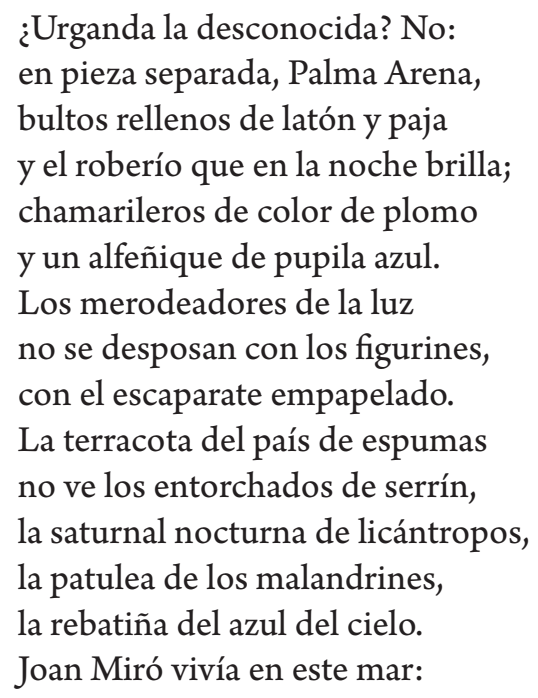


para eso guardamos las palabras, para no conciliarnos con el papel moneda, con el albéitar de botica y pienso.

(Gimferrer, 2012: 33)

Esta pieza está formada por versos endecasílabos, sin un ritmo claro, aunque en este tramo predominen los ritmos sáficos. Se trata de un poema descriptivo: hay muy pocos verbos, también gracias a la elipsis -de manera que hasta el verso 8 no aparece ninguno-. Se define retóricamente por el empleo de las enumeraciones e, incluso, de la estructura paralelística, así como por la casi total ausencia de rima. Urganda no es Urganda, pues en verdad se ha transformado, irónicamente, en Iñaki Urdangarín -yerno del rey Juan Carlos I de España-, tanto por su físico («alfeñique de pupila azul») como por sus actuaciones delictivas (el caso «Palma Arena»y su «roberío»). Evidentemente, aquello que más debe llamar nuestra atención sería el empleo, tan libre como incisivo, de la paronomasia con fines paródicos. No andaríamos muy errados si consideramos este poema un sirventés muy libre en su forma, cuyo contenido oscila entre lo moral y lo político.

Este talante es casi antitético al que muestra José Manuel Lucía Megías en una pieza que permaneció inédita hasta la edición del volumen de su poesía reunida publicado en 2017 (Lucía Megías, 2017: 208-209) y que se titula «Canción para Rafa». Alejado de cualquier viso de ironía, en esta composición de 41 versos el poeta parece reflexionar sobre la triste experiencia íntima de una persona allegada -probablemente quien le da título y a quien se dirigen los versos-, cuya trayectoria vital se ensambla con la del estudioso de los libros de caballerías. A la manera de una epístola, se comparten experiencias: el versículo empleado propicia un tono reflexivo repleto de metáforas vinculadas a la esfera caballeresca. Las alusiones explícitas e implícitas a este universo libresco culminan en la cuarta estrofa (vv. 21-27):

El castillo no es más que una nube; la nube la serpiente de Urganda que llega de lejos con su cargamento de notas y de fuegos diarios.

Pero en el castillo, en ese castillo cerrado a las montañas, abierto al mar, más que por hadas, por una puta se ha bajado el puente de la esperanza; castillo construido con promesas falsas, con ladrillos de mentiras; castillo que se levanta solemne por los aires: sombra de un combate que te rompe el horizonte, acompañado siempre por su inseparable Urganda. (Lucía Megías, 2017: 208)

Esta estrofa, de metro y extensión irregular como el resto de la «canción», confirmaría el profundo conocimiento de la tradición literaria caballeresca por parte de un poeta que es, también, catedrático de Filología Románica de la Universidad Complutense de Madrid y autor de numerosas monografías, traducciones y estudios en torno a la materia de Bretaña y a su progenie hispánica, hasta alcanzar a Cervantes. Lucía Megías remite a un episodio concreto, especialmente celebrado por su espectacularidad, incluido en el libro cuarto de Amadís: la llegada de Urganda a la Ínsula Firme en un barco en forma de gran serpiente (IV, 123). Pero esta remisión fluye y esconde otras dos, pues la Desconocida se asocia con una «puta», según el sorprendente insulto del mago Arcaláus en otra escena (Rodríguez de Montalvo, 1987-1988: 1725), que, tal vez azarosamente, se proyectaría hasta llegar al Quijote apócrifo de Alonso Fernández de Avellaneda (1972: 215-217): «muy puta vieja del tiempo de Mari Castaña, muger del gran judío y más puto de los dos de Santa Susana». 
La función de palabra rima de «Urganda» enfatiza su significación en el diálogo entre el yo poético y su destinatario, a modo de clave personal, como también subraya el recurso a la enumeración, a la anáfora y a la repetición: así, «castillo», metáfora de solidez y evanescencia a un tiempo, se reitera hasta en cinco ocasiones. Esta fortaleza cumple a modo de bisagra que impulsa la sección final del poema, compuesto hacia 2001, en donde se trasciende la anécdota personal y se plantea una meditación de mayor relevancia ética, que culminará con un interrogante retórico, pues se antoja llamada a la acción: « ¿Acaso no ha llegado el momento de conjurar a los necios, / de mirarles cara a cara, de arrancarles la mirada y escupirles nuestro desprecio?» (Lucía Megías, 2017: 209, vv. 40-41).

\section{Urganda la Desconocida en La caja de plata (1985), de Luis Alberto de Cuenca}

En 1984, el filólogo, traductor y poeta Luis Alberto de Cuenca dio a la imprenta uno de los volúmenes que, de manera más clara, marcaron un cambio en el rumbo de la poesía española del último cuarto del siglo XX. Con La caja de plata, publicado por la editorial sevillana Renacimiento en 1985, nuestro autor ofrecía una inflexión en su poética e iniciaba un camino que ha podido, no sin razones, tildarse de «posmoderno». Tal y como ha estudiado Javier Letrán (2005), este carácter derivaba fundamentalmente de su voluntad narrativa a partir de la elección de temas relacionados con la vida cotidiana, sazonados con un claro empleo del humor y la combinación, explícita e implícita, de elementos cultos y populares. Esta mezcla en un poeta como Cuenca propiciaba un claro efecto de desacralización y racionalización, que observaremos repetidamente a lo largo del poemario. De hecho, según confesaba el autor en una conferencia en la sede madrileña de la Fundación Juan March, en este libro fusionó «las sensaciones literarias que emanaban del viejo manual [de literatura] con las nuevas sensaciones que emanaban del libro de mi vida» (Cuenca, 2005: 25).

La caja de plata, que incluye piezas compuestas entre 1979 y 1983, está dividido en tres secciones: las dos primeras, tituladas «El puente de la espada»y «Serie negra» albergan 9 poemas cada una, mientras que la tercera, «La brisa de la calle», ofrece un total de 18 . Diversas han sido las hipótesis críticas sobre su unidad y variedad, pero no cabe duda de que el conjunto ofrece un retrato ascendente de la voz poética, desde la destrucción hasta la plenitud, según han estudiado Juan Antonio Masoliver Ródenas (1986), Javier Gómez-Montero (1994) o Trevor Dadson (1997), entre otros. Diversas son las alusiones al universo cultural del Medioevo, comenzando por la constatación de que el título de la primera parte, «El puente de la espada», remita a un episodio de El caballero de la carreta, de Chrétien de Troyes, que nuestro poeta vertió al español en 1976 junto a Carlos García Gual. De hecho, esta primera sección podría entenderse a la manera de una quête caballeresca: la búsqueda de la identidad perdida. Sin embargo, las referencias directas son escasas y no es hasta la tercera sección que algunos motivos dispersos se interrelacionan con un efecto que busca la sorpresa y el guiño en los lectores más cultivados.

El poema titulado «Urganda la Desconocida» constituye una sorprendente excepción, pues la remisión desde el título al personaje amadisiano hasta los versos finales, en donde se apunta el nombre de Jorge Coci, impresor de la primera edición conservada del Amadís de Rodríguez de Montalvo, pasando por la profecía de los versos 13-17, apelan a una encrucijada cultural insólita, por explícita y, paradójicamente, más equívoca: 


\title{
URGANDA LA DESCONOCIDA
}

\author{
Llueve como si fuera a morir alguien \\ por pecar con las hijas de los hombres. \\ Descorro los visillos. Es Urganda. \\ La de entonces. Sin medias. Va desnuda \\ debajo de un exótico impermeable \\ que finge ser la piel de un tigre. Lleva \\ un niño entre los brazos. No ha perdido \\ un ápice de forma. Viene elástica \\ como el hule de Java. Abro la puerta. \\ Preparo algo caliente. Se lo bebe. \\ Vuelve el color a sus mejillas. Luego \\ mira al recién nacido y profetiza: \\ «Éste será la gala de los héroes \\ de su tiempo, la flor de los amantes. \\ Hará que los tiranos se estremezcan \\ y será el paladín de los humildes. \\ Dará cima a las más altas hazañas.» \\ Dice, y del impermeable se despoja, \\ incendiando mis ojos, como siempre, \\ y prendiéndole fuego al universo.
}

(Con la edición de Coci por almohada, el niño duerme, ajeno a su destino.)

(Cuenca, 2003: 81)

Nuestro poema está formado por 22 versos, los dos últimos dentro de un paréntesis irónicamente informativo cuyo contenido remiten al título. Todos ellos son endecasílabos sin rima convencional, modulados mediante ritmos pertenecientes a la tradición clásica castellana: no hay ni un solo verso sin un ritmo concreto: así, los versos 1 y 18 serían enfáticos, los versos 3, 5, 6, 7, 8, 9, 10 y 15 serían heroicos, el verso 11 sería sáfico y el resto melódicos. Como no existen apenas ritmos enfáticos, que otorgarían un ritmo rápido a la composición, ni sáficos, que lo lentificarían, el ritmo es sereno y equilibrado, por la existencia predominante de los heroicos y de los melódicos. Los versos 4 al 8 presentan encabalgamientos abruptos, justo en el momento en el que describe la sensualidad de Urganda, probablemente para intensificar los sentimientos del yo poético y su masculinidad. Desde esta perspectiva, resulta interesante subrayar que esa primera persona del singular está presente; sin embargo, Urganda no es el tú explícito, sino que se refiere a ella en tercera persona, y sólo interviene, en estilo directo, cuando se reproducen sus palabras. Es como el intento de dar cuerpo a la Desconocida, de materializar el personaje sobrenatural, pero manteniendo sus características intemporales, según apuntalan los dos versos iniciales.

En opinión de Juan José Lanz (apud Cuenca, 2006: 59), «el sueño profético se funde con la experiencia erótica, y el plano onírico-literario (con la alusión al personaje de Amadís de Gaula) con el erótico-amoroso, para crear un fantástico arquetipo femenino de indudable modernidad». Las dos figuras retóricas más importantes serían la metáfora fosilizada del penúltimo verso («incendiando», pues remite a la pasión amorosa) y, sobre todo, la hipérbole del antepenúltimo verso, donde se refiere a la trascendencia y la importancia mayúscula para el yo poético («prendiéndole fuego al 
universo»). Resulta interesante destacar cómo el carácter feérico del personaje original se combina con una serie de términos que lo emplazan en la esfera cotidiana: «visillos», «impermeable», una «piel de tigre» falsa, «hule»... Igualmente, resulta elocuente la fidelidad al Amadís de Garci Rodríguez de Montalvo, mediante la inclusión de la profecía citada al inicio del presente trabajo.

De acuerdo con Javier Letrán ( apud Cuenca, 2003: 100-101), la génesis de este poema derivaría de una anécdota real -cuyo contenido no explicita- que le habría contado al poeta su segunda esposa, Julia Barella. Aquello que resulta tanto o más interesante es que Luis Alberto de Cuenca aproveche parte de un poema anterior, titulado «La visita», que había visto la luz en 1984, y en donde el personaje descrito no remite en ninguna instancia a la Urganda amadisiana. Sus primeros versos eran:

No lleva medias ni liguero.

Va desnuda debajo del impermeable,

de un impermeable que simula ser una piel de tigre,

con rayas que parecen pinceladas de un calígrafo chino,

con trazos fúnebres y oscuros sobre el plástico transparente.

La distancia entre un poema y otro es casi abismal, tanto en el plano formal como en el del contenido, pues mientras que «La visita» se ubicaría cómodamente en la órbita de los versos de la segunda sección de La caja de plata, «Urganda la Desconocida» se emplaza en el nudo de significaciones de la última. ¿Cuál es la razón que puede explicar su aparición? Las respuestas deben ser diversas y complementarias.

En un artículo consagrado al análisis de la presencia de la mitología clásica en la obra poética de Luis Alberto de Cuenca, sus autores sugerían que dicha incorporación, muy rica y dúctil, podía cumplir varios propósitos, como son la alusión puntual, de carácter erudito, su uso como anécdota principal del poema y el empleo del episodio mitológico como correlato objetivo del sentimiento o vivencia que el autor quiere expresar en el texto (Martínez Sariego y Laguna Mariscal, 2010). En «Urganda la Desconocida», la remisión al personaje amadisiano seguiría un muy parecido proceso de acomodación, pero su originalidad radicaría en la fusión de estos tres objetivos, convergencia que propiciaría una propuesta de lectura más compleja.

A mi juicio, Luis Alberto de Cuenca estaría apostando por un sincretismo de efectos hiperbólicos. En primer lugar, como poeta culto y gran conocedor de la tradición cortesana medieval, estaría jugando a ser un nuevo Garci Rodríguez de Montalvo: refundidor de un texto previo del que borra matices y al que añade significados. En segundo lugar, presenta un poema cuya versificación clásica y su ritmo sereno albergan la heterodoxia a través del plano del contenido, abierto a significaciones antitéticas, y de la mezcla de contextos antiguos y contemporáneos. En tercer lugar, la profecía de Urganda estaría abriendo una vía interpretativa de todo el poemario, que se orientaría hacia la salvación y liberación del yo poético. Pero, además, en cuarto lugar, con el poema «Urganda la Desconocida», Luis Alberto de Cuenca estaría emplazándose en una genealogía literaria posmoderna que le conduciría desde las fuentes remotas del personaje -la materia de Bretaña-, pasando por los libros de caballerías del Renacimiento, hasta llegar a la primera parte del Quijote; al contrario que Fernández de Avellaneda, quien tildó a Urganda de «puta vieja» en su Quijote apócrifo, Cuenca la convierte en una joven atractiva y exótica, a la manera de una vidente desnortada bajo la lluvia que predice el futuro, pero que acarrea a un recién nacido, tal vez su propio hijo. Y, por supuesto, en último lugar, también con esta refundición, el autor de La caja de plata estaría 
emulando y rindiendo homenaje al patrón desmitificador e irónico con que Miguel de Cervantes bañó el personaje en sus versos de cabo roto.

\section{Bibliografía}

Beltrán, Rafael (1997), «Urganda, Morgana y Sibila: el espectáculo de la nave profética en la literatura de caballerías», en The Medieval Mind. Hispanic Studies in Honour of Alan Deyermond, eds. Ian Macpherson y Ralph Penny, Londres, Tamesis, pp. 21-47.

Bognolo, Anna (1994-1996), «Gli encanti di Urganda: magia come spettacolo nei libros de caballerías», Studi Ispanici, 30, pp. 111-128.

CAmpos García Rojas, Axayácatl (2013), «“Urganda, la otrora gran sabidora”: evolución y refuncionalización», en Palmerín y sus libros: 500 años, eds. Aurelio González et al., México, D.F., El Colegio de México, pp. 343-365.

Cervantes, Miguel de (1980 [1605]), Don Quijote de la Mancha, ed. Martín de Riquer, Barcelona, Planeta.

Cuenca, Luis Alberto de (2003 [1985]), La caja de plata, ed. Javier Letrán, Madrid, Fondo de Cultura Económica.

(2005), Luis Alberto de Cuenca: Póetica y Poesía, Madrid, Fundación Juan March. (2006), Poesía 1979-1996, ed. Juan José Lanz, Madrid, Cátedra.

DADSON, Trevor J. (1997), «Art and the Distancing of Grief: Luis Alberto de Cuenca's La caja de plata and its Golden-Age Antecedents», Revista Hispánica Moderna, 50, pp. 363-381.

FARRÉ VIDAL, Judith (2007), «La presencia festiva de El Quijote en los virreinatos americanos», en Dramaturgia festiva y cultura nobiliaria en el Siglo de Oro, eds. Bernardo José García García y María Luisa Lobato López, Madrid, Iberoamericana, pp. 385-415.

Fernández de Avellaneda, Alonso (1972 [1614]), Don Quijote de la Mancha, ed. Martín de Riquer, Madrid, Espasa-Calpe, 2 vols.

Gimferrer, Pere (2012), Alma Venus, Barcelona, Seix Barral.

Gómez-Montero, Javier (1994), «Poética de la postmodernidad y praxis de la parodia en Poesía (1970-1989) de Luis Alberto de Cuenca», en Actas del IX Simposio de la Sociedad Española de Literatura General y Comparada, Zaragoza, Universidad de Zaragoza, pp. 133-151.

Letrán, Javier (2005), La poesía postmoderna de Luis Alberto de Cuenca, Sevilla, Renacimiento.

Lucía Megías, José Manuel (2017), El único silencio. Poesía reunida, 1998-2017, Madrid, Sial.

Martínez Sariego, Mónica M. y Gabriel Laguna Mariscal (2010), «La mitología clásica en la poesía de Luis Alberto de Cuenca (1971-1996)», Cuadernos de Filología Clásica. Estudios Latinos, 30.2, pp. 381-413.

Masoliver Ródenas, Juan Antonio (1986), «Luis Alberto de Cuenca: historia de un egocidio», Hora de Poesía, 43, pp. 75-80.

MÉRIDA JIMÉNEZ, Rafael M. (2001), «Fuera de la orden de natura»: magias, milagros y maravillas en el «Amadís de Gaula», Kassel, Reichenberger.

(2008), «El Quijote de Alonso Fernández de Avellaneda y la tradición amadisiana (sobre una “puta vieja del tiempo de Mari Castaña”)», Scriptura, 19-20, pp. 75-93.

(2016), «Las retóricas del palimpsesto y la Edad Media en la poesía de Pere Gimferrer», Revista de Filología Románica, 33.1, pp. 75-84.

Rodríguez de Montalvo, Garci (1987-1988 [c. 1495]), Amadís de Gaula, ed. Juan Manuel Cacho Blecua, Madrid, Cátedra, 2 vols. 
